\title{
ANALISIS TITIK IMPAS AGROINDUSTRI KREMES (Studi Kasus pada IKM Kremes "KURNIA" di Desa Sindangsari Kecamatan Cikoneng Kabupaten Ciamis)
}

\author{
BREAK EVEN POINT ANALYSIS OF KREMES AGROINDUSTRY \\ (Case Study at IKM Kremes “KURNIA” in Sindangsari Village, \\ Cikoneng District, Ciamis Regency)
}

\author{
ELSA TIANI NURYANA DEVIS ${ }^{* 1}$, DINI ROCHDIANI ${ }^{2}$, \\ MUHAMAD NURDIN YUSUF ${ }^{1}$ \\ ${ }^{1}$ Fakultas Pertanian Universitas Galuh \\ ${ }^{2}$ Fakultas Pertanian Universitas Padjadjaran \\ *E-mail : elsatianinuryanadevis@gmail.com
}

\begin{abstract}
ABSTRAK
Kecamatan Cikoneng merupakan salah satu sentra industri pengolahan hasil pertanian ke-7 terbesar di Kabupaten Ciamis. Umumnya agroindustri kecil di perdesaan jarang menghitung biaya yang dikeluarkannya secara detail, hal inilah yang menyebabkan tidak dapat diketahuinya pendapatan yang sebenarnya diperoleh secara pasti. Penelitian ini bertujuan untuk mengetahui : (1) Besarnya biaya, penerimaan dan pendapatan usaha kremes pada IKM Kremes "KURNIA" dalam satu kali proses produksi. (2) Besarnya titik impas nilai penjualan, titik impas volume produksi, dan titik impas harga kremes pada IKM Kremes "KURNIA" dalam satu kali proses produksi. Penelitian ini dilakukan dengan metode studi kasus di Desa Sindangsari Kecamatan Cikoneng Kabupaten Ciamis yang ditentukan secara sengaja (purposive sampling). Metode analisis data yang digunakan dalam penelitian ini adalah analisis biaya, penerimaan, pendapatan dan titik impas. Hasil penelitian ini menunjukan bahwa : (1) Biaya produksi yang dikeluarkan oleh pengusaha kremes pada IKM kremes "KURNIA" Rp 2.860.060,29, besarnya penerimaan $\mathrm{Rp} 3.600 .000,00$, besarnya pendapatan $\mathrm{Rp} 739.939,71$. (2) Titik impas nilai penjualan kremes dalam satu kali proses produksi Rp 306.532 .56 ,sementara titik impas volume produksi 102,17 pak, dan titik impas harga $\mathrm{Rp} 2.382,38$ per pak.
\end{abstract}

Kata Kunci : agroindustri, kremes, titik impas

\begin{abstract}
Cikoneng District is the $7^{\text {th }}$ biggest agricultural product processing industrial center in Ciamis Regency. In general, small agroindustry in village doesn't often count costs incurred in detail. It makes the income is unknown clearly. This research aimed to find out: (1) The amount of costs, revenues and income of the kremes bussines at IKM Kremes "KURNIA" in one production process. (2) The amount of the break even point of sale value, the break even point of production volume, and the break even point of price of kremes at IKM Kremes "KURNIA" in one production process. This research was conducted with a case study method in Sindangsari Village, Cikoneng District, Ciamis Regency determined intentionally (purposive sampling). Method of data analysis used in this research were cost, revenue, income and break even point analysis. The results of the research showed that: (1) Production costs incurred by the kremes entrepreneur at IKM Kremes "KURNIA" was Rp. 2,860,060.29, the amount of revenue was $R p .3,600,000.00$, the amount of income was $R p .739,939.71$. (2) The break even point of the sales value of kremes in one production process was $R p$ 306,532.56, whereas the break even point of poduction volume was 102.17 packs, and the break even point of price was $R p$ 2,382.38 per pack.
\end{abstract}

Key Words: agroindustry, kremes, break even point. 


\section{PENDAHULUAN}

Industri ialah suatu kegiatan ekonomi yang mengolah bahan mentah, bahan baku, barang setengah jadi atau barang jadi menjadi barang yang memiliki nilai tinggi untuk penggunaannya, termasuk kegiatan rancang bangun dan perekayasaan industri (UU No.5 Tahun 1984 Tentang Perindustrian). Umumnya, semakin maju tingkat perkembangan perindustrian di suatu daerah, maka jumlah dan macam industri akan semakin banyak, dan sifat kegiatan dan usahanya pun akan semakin kompleks. Pengklasifikasiannya pun berbeda-beda. Salah satunya adalah klasifikasi industri berdasarkan bahan mentah. Klasifikasi industri berdasarkan bahan mentah dapat dibedakan menjadi tiga jenis, yaitu industri pertanian, industri pertambangan dan industri jasa (Anonim, 2019).

Industri pertanian merupakan suatu industri yang didalamnya terdapat kegiatan pengolahan bahan mentah dari hasil pertanian (Anonim, 2019). Ada banyak tujuan dari proses pengolahan bahan mentah ini, diantaranya adalah untuk meningkatkan kualitas bahan dan memperpanjang daya simpannya sehingga nantinya bahan hasil pertanian ini mampu memperoleh nilai jual yang lebih tinggi.
Industri pengolahan hasil pertanian memiliki kontribusi yang cukup besar terhadap pembangunan pertanian. Pembangunan pertanian itu sendiri merupakan suatu hal yang tidak bisa ditawar lagi terutama bagi negara-negara yang sedang berkembang, yang pada umumnya jumlah penduduknya besar, wilayahnya luas dan sumber daya alamnya belum diolah (Subandi, 2014). Jika industri pengolahan hasil pertanian terus dikembangkan maka permintaan akan hasil-hasil pertanian pun akan meningkat sehingga produksi dan pendapatan petani pun akan ikut meningkat. Selain itu, industri pengolahan hasil pertanian mampu mendorong terciptanya kesempatan kerja di perdesaan dengan pendapatan yang layak. Udayana (2013) menyatakan bahwa industri pengolahan hasil pertanian merupakan sektor penggerak utama perkembangan sektor pertanian dalam kerangka pembangunan pertanian.

Kabupaten Ciamis memiliki banyak industri pengolahan hasil pertanian yang tersebar di beberapa kecamatan, salah satunya adalah di Kecamatan Cikoneng (Dinas Perindustrian dan Perdagangan Kabupaten Ciamis, 2019). Masyarakat di Kecamatan Cikoneng kebanyakan mengolah hasil pertaniannya menjadi makanan ringan, kue kering dan kerupuk. 
Makanan ringan yang diproduksinya pun sangat beranekaragam, salah satunya adalah makanan ringan dengan nama "Kremes" yang merupakan makanan terbuat dari ubi kayu dengan pengolahan yang terbilang mudah.

Usaha kremes dapat dijumpai di beberapa desa di Kecamatan Cikoneng, dan yang paling dominan itu berada di Desa Sindangsari. Desa Sindangsari memiliki 2 IKM (Industri Kecil Menengah) Kremes, yaitu IKM Kremes "LEGIT" dan IKM Kremes "KURNIA". IKM kremes tersebut mampu memproduksi ratusan hingga ribuan pak kremes setiap harinya (Kantor Kecamatan Cikoneng, 2019).

Pada umumnya agroindustri kecil di perdesaan jarang menghitung biaya yang dikeluarkannya secara detail, hal inilah yang menyebabkan tidak dapat diketahuinya pendapatan yang sebenarnya diperoleh secara pasti. Hal ini sejalan dengan Sopiah dan Syihabudhin (2008) yang menyatakan bahwa secara umum usaha kecil memiliki banyak karakteristik, diantaranya adalah memiliki modal yang terbatas, sistem pembukuannya yang sederhana dan cenderung tidak mengikuti kaidah administrasi pembukuan standar, serta terbatasnya pengalaman manajerial dan mengelola perusahaan.
Berdasarkan dari latar belakang, maka penulis tertarik untuk melakukan penelitian tentang Analisis Titik Impas Agroindustri Kremes pada IKM Kremes "KURNIA".

\section{Tujuan Penelitian}

Tujuan penelitian, ini adalah untuk mengetahui :

1. Besarnya biaya, penerimaan dan pendapatan usaha kremes pada IKM Kremes "KURNIA" dalam satu kali proses produksi.

2. Besarnya titik impas nilai penjualan, titik impas volume produksi, dan titik impas harga kremes pada IKM Kremes "KURNIA" dalam satu kali proses produksi

\section{METODE PENELITIAN}

Jenis penelitian yang digunakan adalah metode studi kasus pada IKM Kremes "KURNIA" yang terletak di Desa Sindangsari Kecamatan Cikoneng Kabupaten Ciamis. Menurut Sujarweni (2014), studi kasus adalah penelitian mengenai manusia (dapat suatu kelompok, organisasi maupun individu), peristiwa, latar secara mendalam, tujuan dari penelitian ini untuk mendapatkan gambaran tentang suatu kasus yang diteliti 
secara mendalam. Pengumpulan datanya diperoleh dari wawancara dan observasi.

Teknik pengumpulan data yang dikumpulkan yaitu meliputi data primer dan data sekunder.

Pengambilan sampel dilakukan secara sengaja (purposive sampling) terhadap IKM Kremes "KURNIA" dengan pertimbangan adanya kendala dalam pengambilan data. Menurut Sugiyono (2006), teknik penarikan sampel menggunakan purposive sampling yaitu sampel yang diambil secara sengaja (dipilih) untuk kepentingan tertentu dari peneliti.

\section{Rancangan Analisis Data}

Rancangan analisis data yang dilakukan dalam penelitian ini antara lain

1. Analisis Biaya

Untuk menghitung besarnya biaya total (Total Cost) diperoleh dengan cara menjumlahkan biaya tetap (Fixed Cost) dengan biaya variabel (Variable Cost) menggunakan rumus (Suratiyah, 2015) :

$$
\mathrm{TC}=\mathrm{FC}+\mathrm{VC}
$$

Dimana :

$\mathrm{TC}=$ Total Cost (Biaya Total $)$

$\mathrm{FC}=$ Fixed Cost (Biaya Tetap)

$\mathrm{VC}=$ Variable Cost (Biaya Variabel)
2. Analisis Penerimaan

Secara umum perhitungan penerimaan total (Total Revenue/TR) adalah perkalian antara jumlah produksi (Y) dengan harga jual (Py) dan dinyatakan dengan rumus (Suratiyah, 2015):

$$
\mathrm{TR}=\mathrm{Py} . \mathrm{Y}
$$

Dimana :

$\mathrm{TR}=$ Total Revenue $($ Penerimaan Total)

Py $=$ Harga produk

$\mathrm{Y}=$ Jumlah produksi

3. Analisis Pendapatan

Pendapatan adalah selisih antara penerimaan (TR) dan biaya total (TC) dan dinyatakan dengan rumus (Suratiyah, 2015) :

$\mathrm{I}=\mathrm{TR}-\mathrm{TC}$

Dimana :

$\mathrm{I}=$ Income (Pendapatan)

$\mathrm{TR}=$ Total Revenue $($ Penerimaan Total $)$

$\mathrm{TC}=$ Total Cost $($ Biaya Total $)$

4. Analisis Titik Impas (Break Even Point)

Untuk mengetahui titik impas dihitung dengan menggunakan rumus (Suratiyah, 2015) :

a. Titik impas nilai penjualan $(\mathrm{Rp})$ :

$$
\operatorname{BEPnp}(\mathrm{Rp})=\frac{\mathrm{TFC}}{1-\frac{\mathrm{TVC}}{\mathrm{TR}}}
$$


b. Titik impas volume produksi dalam unit (Pak) :

BEPvp $($ Pak $)=\frac{\text { BEPnp }}{\text { Harga }}$

c. Titik impas harga (Rp/pak) :

$\mathrm{BEPh}(\mathrm{Rp} / \mathrm{pak})=\frac{\mathrm{TC}}{\text { Total Produksi }}$

\section{Tempat dan Waktu Penelitian}

Tempat penelitian dilaksanakan di Desa Sindangsari, Kecamatan Cikoneng, Kabupaten Ciamis.

1. Tahap persiapan, yaitu survey pendahuluan dan penulisan Usulan Penelitian dilaksanakan pada bulan April 2019.

2. Tahap pengumpulan data dari lapangan, yaitu pengumpulan data primer dan sekunder dilaksanakan pada bulan Mei 2019.

3. Tahap pengolahan dan analisis data, serta penulisan Skripsi dilaksanakan pada bulan Juni 2019 sampai dengan selesai.

\section{HASIL DAN PEMBAHASAN}

\section{Analisis Usaha Agroindustri Kremes}

Analisis usaha agroindustri kremes terdiri dari analisis biaya, analisis penerimaan, analisis pendapatan dan analisis titik impas (Break-Even Point) yang dihitung dalam satu kali proses produksi.

\section{Analisis Biaya}

\section{Biaya Tetap}

Biaya tetap adalah biaya yang besarnya tidak terpengaruh oleh volume produksi, yang terdiri dari pajak bumi bangunan, penyusutan alat, izin usaha, NPWP dan bunga modal tetap dalam satu kali proses produksi. Dalam pelaksanaan produksi kremes, IKM Kremes "KURNIA" mengeluarkan biaya tetap $\mathrm{Rp} 70.502,49$ dalam satu kali proses produksinya. Penggunaan biaya tetap yang paling dominan terdapat pada penyusutan alat yaitu $\mathrm{Rp}$ 67.349,52 atau 95,53\% dari jumlah biaya tetap. Hal ini disebabkan karena jumlah aset yang digunakan dalam agroindustri kremes cukup banyak. 


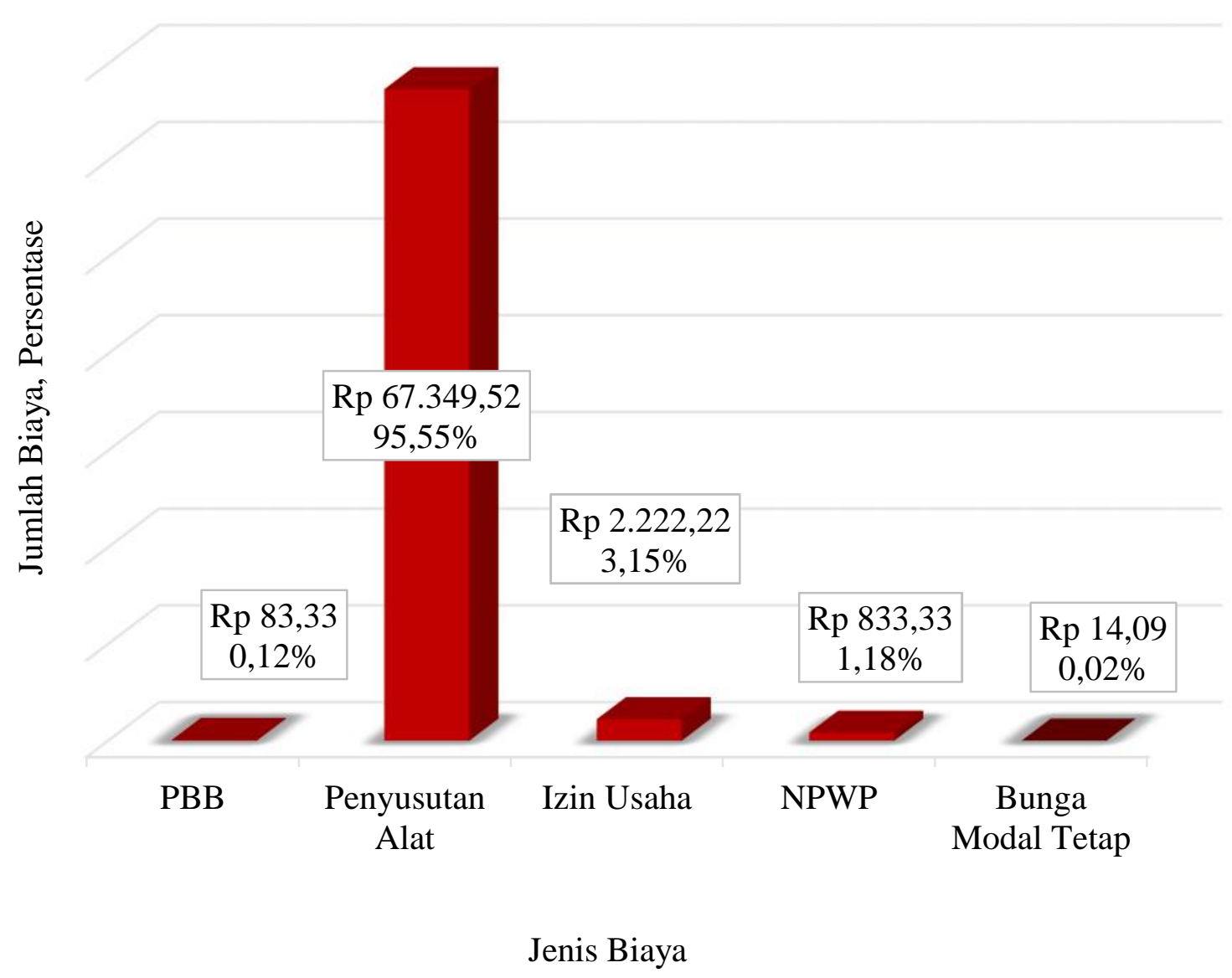

\section{Gambar 9. Biaya Tetap Agroindustri Kremes dalam Satu Kali Proses Produksi}

Sumber : Data Primer Diolah (2019)

\section{Biaya Variabel}

Biaya variabel atau biaya tidak tetap yaitu biaya yang besarnya dipengaruhi oleh volume produksi dan sifatnya habis dalam satu kali proses produksi. Besarnya biaya variabel yang dikeluarkan oleh agorindustri kremes pada IKM Kremes "KURNIA" adalah $\quad \operatorname{Rp} 2.789 .557,80$.
Penggunaan biaya variabel paling dominan terdapat pada pembelian ubi kayu yaitu Rp 780.000,00 atau 27,96\% dari jumlah biaya variabel. Hal ini disebabkan karena jumlah penggunaan ubi kayu dalam satu kali proses produksi sangat banyak dan harganya cukup tinggi. 


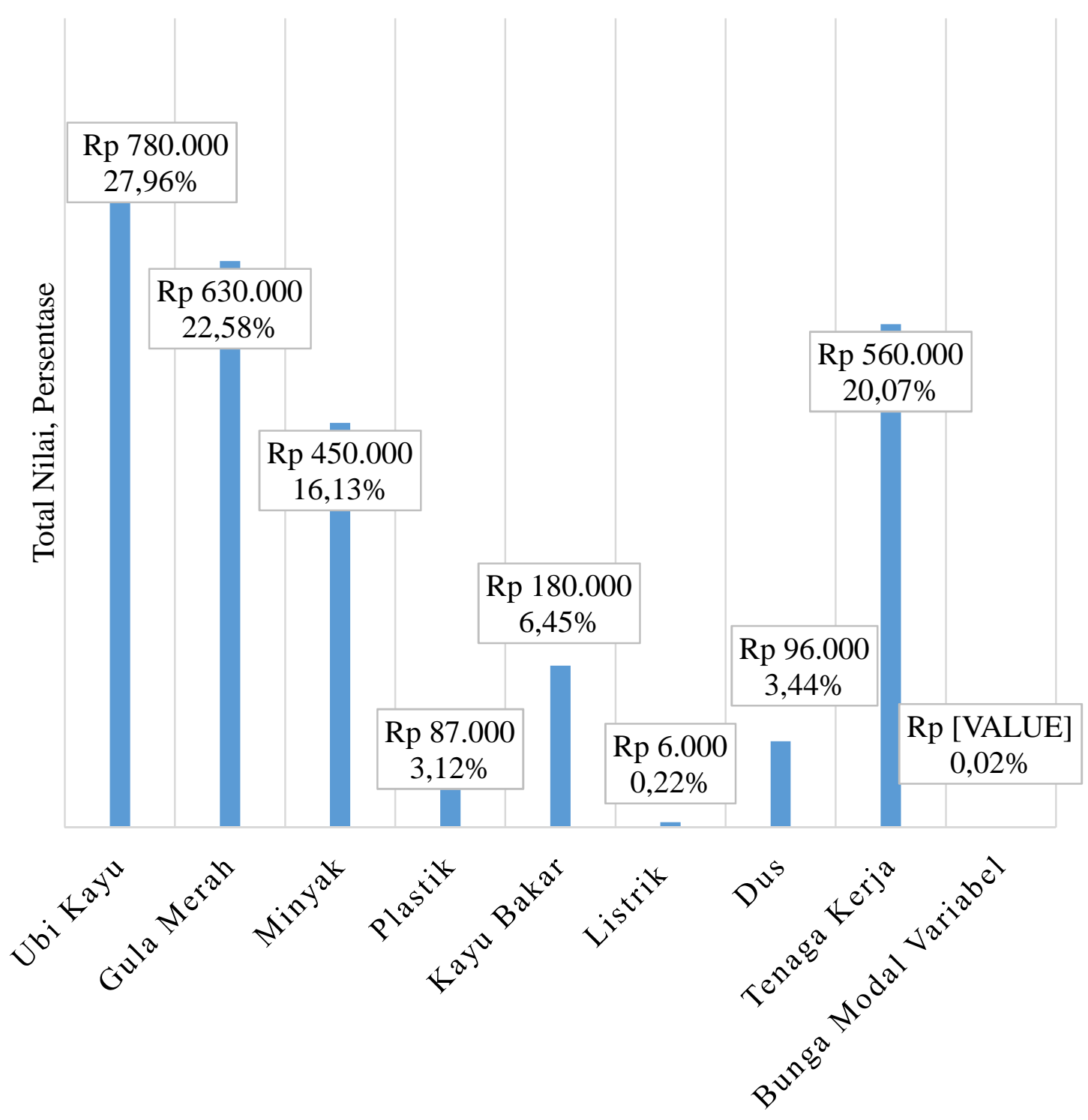

Unsur Biaya

\section{Gambar 10. Biaya Variabel Agroindustri Kremes dalam Satu Kali Proses Produksi}

Sumber : Data Primer Diolah (2019)

\section{Total Biaya}

Biaya total merupakan hasil penjumlahan dari biaya tetap dan biaya variabel. Dari perhitungan dapat diketahui biaya tetap yang dikeluarkan agroindustri kremes yaitu $\mathrm{Rp} 70.502,49$ dan biaya variabel Rp 2.789.557,80, sehingga biaya total yang digunakan Rp 2.860.060,29.

\section{Analisis Penerimaan dan Pendapatan}

Penerimaan merupakan hasil perkalian dari volume produksi dengan harga jual yang berlaku pada saat 
penelitian. Jumlah produk kremes yang dihasilkan dalam satu kali proses produksi yaitu 1200 pak, sedangkan harga per paknya yaitu Rp 3000,00. Maka penerimaan yang diperoleh pengusaha kremes yaitu Rp 3.600.000,00.

Pendapatan merupakan selisih dari total penerimaan dengan total biaya dalam satu kali proses produksi. Penerimaan agroindustri kremes adalah $\mathrm{Rp}$ 3.600.000,00 sedangkan total biayanya adalah Rp 2.860.060,29, maka pendapatan yang diperoleh pengusaha kremes dalam satu kali proses produksi adalah $\mathrm{Rp}$ $739.939,71$.

\section{Analisis Titik Impas (Break Even Point)}

\section{Agroindustri Kremes}

Analisis titik impas adalah suatu analisis yang bertujuan untuk menemukan satu titik dalam unit, rupiah atau pun harga, yang menunjukkan biaya sama dengan penerimaan. Berdasarkan data biaya tetap, biaya variabel dan penerimaan dari responden yang sudah diolah kembali maka nilai titik impas akan dapat diketahui. Adapun analisis titik impas yang dihitung adalah titik impas nilai penjualan, titik impas volume produksi dan titik impas harga.

\section{Analisis Titik Impas Nilai Penjualan (Penerimaan)}

$\operatorname{BEPnp}(\mathrm{Rp})=\frac{\mathrm{TFC}}{1-\frac{\mathrm{TVC}}{\mathrm{TR}}}$
$\operatorname{BEPnp}(\mathrm{Rp})=\frac{70.502,49}{1-\frac{2.789 .557,8}{3.600 .000,00}}$

BEPnp (Rp) $=\frac{70.502,49}{1-0,77}$

$\operatorname{BEPnp}(\mathrm{Rp})=\frac{70.502,49}{0,23}=306.532,56$

Hasil analisis menunjukkan bahwa nilai jual minimum yang harus diterima pengusaha agroindustri kremes untuk mencapai titik impas dalam satu kali proses produksi yaitu Rp 306.532,56. Jika perusahaan beroperasi kurang dari BEP maka perusahaan akan mengalami kerugian.

\section{Analisis Titik Impas Volume Produksi}

$$
\begin{aligned}
\operatorname{BEPvp}(\text { Pak }) & =\frac{\text { BEPnp }}{\text { Harga }} \\
\text { BEPvp (Pak) } & =\frac{306.532,56}{3.000,00} \\
& =102,17
\end{aligned}
$$

Hasil analisis menunjukkan bahwa titik impas volume produksi agroindustri kremes dalam satu kali proses produksi yaitu 102,17 pak, artinya agroindustri kremes ini benar-benar menguntungkan

karena volume produksi agroindustri kremes sudah lebih tinggi dari BEP, 
sehingga pengusaha tidak mengalami kerugian sama sekali.

\section{Analisis Titik Impas Harga}

$\mathrm{BEPh}(\mathrm{Rp} / \mathrm{Pak})=\frac{\mathrm{TC}}{\text { Total Produksi }}$

$\mathrm{BEPh}(\mathrm{Rp} / \mathrm{Pak})=\frac{2.860 .060,29}{1.200}$

$$
=2.383,38
$$

Hasil analisis menunjukkan harga jual minimum hasil produksi yang harus dikeluarkan pengusaha agroindustri kremes agar mencapai titik impas dalam satu kali proses produksi yaitu Rp 2.383,38 per pak. Apabila harga jual per pak kurang dari Rp 2.383,38 maka perusahaan akan mengalami kerugian.

Secara grafik titik impas agroindustri kremes pada IKM Kremes "KURNIA" dalam satu kali proses produksi dapat dilihat pada Gambar 11.

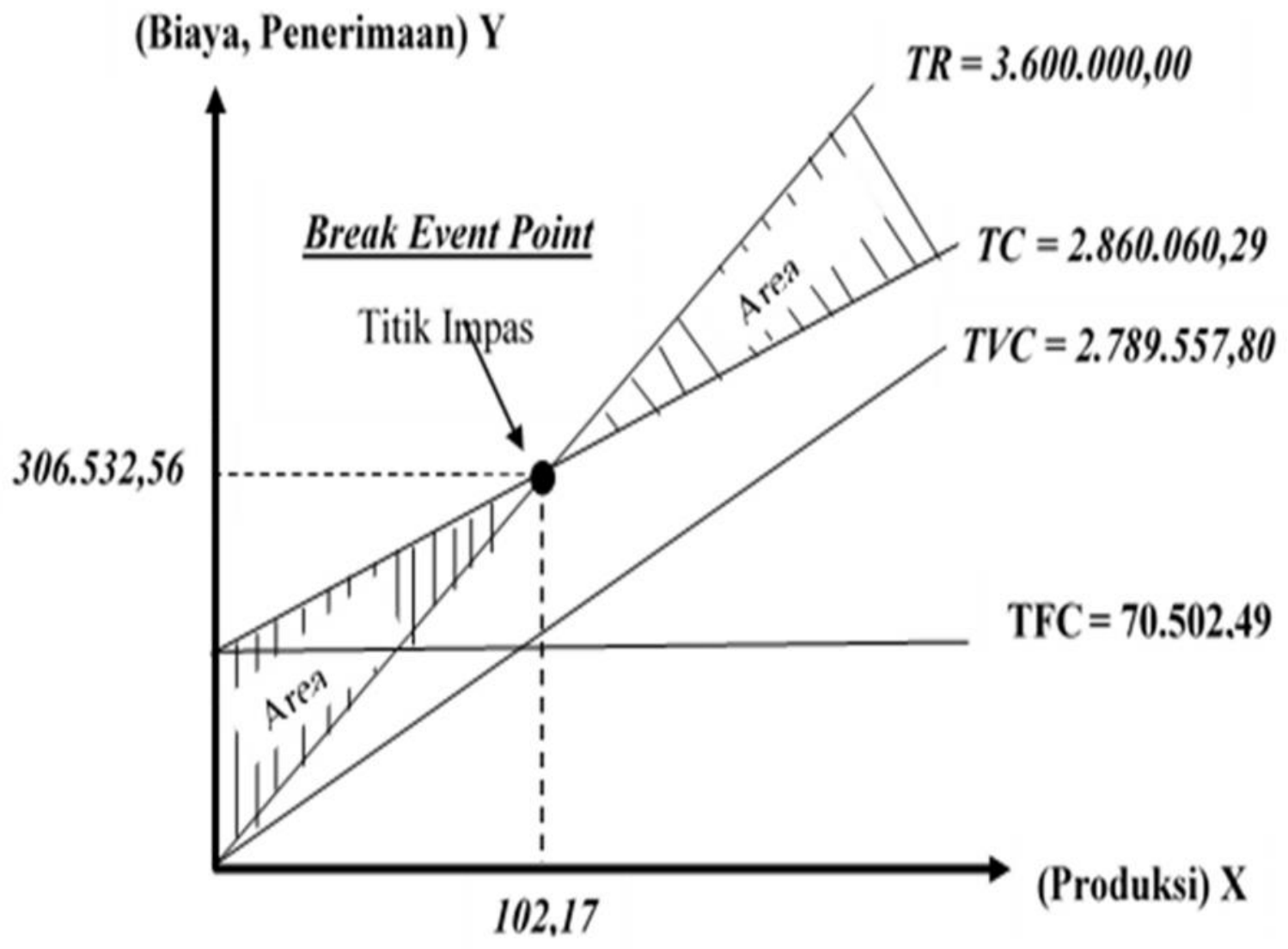

Gambar 11. Grafik BEP (Break Even Point) 


\section{KESIMPULAN DAN SARAN}

\section{Kesimpulan}

Berdasarkan hasil penelitian dan pembahasan dapat diambil kesimpulan sebagai berikut :

1. Besarnya biaya produksi yang dikeluarkan oleh pengusaha kremes pada IKM Kremes "KURNIA" adalah Rp 2.860.060,29, penggunaan biaya produksi yang paling dominan terdapat pada jenis biaya variabel yaitu untuk biaya pembelian ubi kayu Rp 780.000,00, produksi yang dihasilkan 1.200 pak kremes, harga produk $\mathrm{Rp}$ 3.000,00 per pak kremes, besarnya penerimaan yang diperoleh pengusaha kremes $\mathrm{Rp}$ 3.600.000,00, besarnya pendapatan yang diperoleh pengusaha kremes $\operatorname{Rp} 739.939,60$.

2. Besarnya titik impas nilai penjualan (penerimaan) kremes pada IKM Kremes “KURNIA” Rp 306.532,56, untuk titik impas volume produksi 102,17 pak dan untuk titik impas harga penjualan produk Rp 2.383,38 per pak dalam satu kali proses produksi.

\section{Saran}

Berdasarkan kesimpulan penelitian , maka diajukan saran sebagai berikut :
1. Pengusaha hendaknya tetap melaksanakan usaha kremes dan diharapkan pengusaha dapat membuat inovasi kremes berbagai rasa yang sesuai dengan selera konsumen.

2. Perlu peningkatan volume produksi sehingga akan terjadi peningkatan pendapatan bagi pengusaha.

\section{DAFTAR PUSTAKA}

Anonim A. 2019. Klasifikasi Industri dihttps://id.wikipedia.org/wiki/Kate gori:Klasifikasi_Industri (diakses 20 April 2019)

Disperindag Kabupaten Ciamis. 2019. Data Sentra Industri Pengolahan Hasil Pertanian di Kabupaten Ciamis Tahun 2019. Ciamis.

Kantor Kecamatan Cikoneng. 2019. Data IKM Kremes Wilayah Kecamatan

\section{Cikoneng. Cikoneng.}

Sopiah dan Syihabudhin. 2008. Manajemen Bisnis Ritel. Andi Offset. Yogyakarta.

Subandi. 2014. Ekonomi Pembangunan. Alfabeta. Bandung.

Sugiyono. 2006. Metode Penelitian Bisnis. Alfabeta. Bandung.

Sujarweni. 2014. Metodologi Penelitian. Pustaka Baru Press. Yogyakarta.

Suratiyah, K. 2015. Ilmu Usahatani. Penebar Swadaya. Jakarta.

Udayana, GB. 2013. Peran Agroindustri dalam Pembangunan Pertanian. Jurnal Singhadwala, Edisi 44, Februari 2011. 